\title{
Comparison of methods for isolating Mycobacterium avium-intracellulare from blood of patients with AIDS
}

\author{
D C SHANSON, M S DRYDEN St Stephen's Hospital, London
}

SUMMARY A variety of blood culture media were compared to determine the optimal method for the isolation of Mycobacterium avium-intracellulare (MAI) from the blood of patients with AIDS. Simulated laboratory blood cultures and clinical blood cultures were tested. Glucose broth, Bactec aerobic medium, Kirschner's medium, and Bactec Middlebrook medium supported the growth of MAI. The Isolator system, a lysis centrifugation method, facilitated the most rapid isolation of MAI $(\mathrm{p}=0.001)$. The Bactec Middlebrook medium gave the most rapid detection rate $(\mathrm{p}=0.001)$ as acid fast bacilli could be stained by the Ziehl-Neelson method before colonies were isolated in the Isolator system. The growth index readings did not reliably predict mycobacterial growth in the two radiometric media tested.

Although several methods may be used to isolate MAI from blood, the most rapid and sensitive method is the Isolator system used in combination with the Bactec Middlebrook medium.

Disseminated mycobaterial infection, particularly with Mycobacterium avium intracellulare (MAI), is common in patients with AIDS. ${ }^{1-5}$ We compared the in vitro growth of MAI in several conventional and specialised blood culture media, and also carried out a clinical comparison of these media.

\section{Material and methods}

Kirschner broth culture of five strains of MAI, cultured from different patients with AIDS, were inoculated in whole human blood to give two final concentrations. A heavy inoculum represented 50 to 500 colony forming units (cfu) $/ \mathrm{ml}$ of blood, and a light inoculum 1 to $5 \mathrm{cfu} / \mathrm{ml}$ of blood.

Blood containing both concentrations of organisms was inoculated into a variety of commercial blood culture media (table 1). The media tested were digest broth with $0.1 \%$ glucose and $0.05 \%$ liquoid $(30 \mathrm{ml})$ (Southern Group Laboratories), Bactec radiometric tryptic soy broth (30 ml) (Becton Dickinson) (Bactec aerobic), Bactec radiometric 7H12 Middlebrook medium (4 ml) (Becton Dickinson), a standard liquid Kirschner medium (30 ml) (Oxoid), and Isolator (Du Pont), a lysis centrifugation method. This last method contains saponin which produces cell lysis, and sodium polyanetholesulphonate, and which acts as an anticoagulant, neutralises the bactericidal properties

Accepted for publication 5 January 1988 of blood, and inhibits phagocytosis. The Isolator tubes were centrifuged at $2000 \mathrm{rpm}$ for 30 minutes. The supernatant was discarded and the deposit was inoculated on a Lowenstein Jensen slope and 7 H11 agar which was treated in the same way as the other plates. Two anaerobic media were also tested: a brain heart infusion broth with cysteine and panmede (50

Table 1 Simulated laboratory blood cultures

\begin{tabular}{|c|c|c|c|}
\hline Media & $D a y$ & $\begin{array}{l}\text { Heavy inoculum } \\
(50-500 \mathrm{cfu} / \\
\mathrm{ml})\end{array}$ & $\begin{array}{l}\text { Light inoculum } \\
(I-5 \mathrm{cfu} / \mathrm{ml})\end{array}$ \\
\hline Bactec aerobic & $\begin{array}{l}14 \\
21 \\
32\end{array}$ & $\begin{array}{l}32 \\
36 \\
36\end{array}$ & $\begin{array}{r}0 \\
15 \\
33\end{array}$ \\
\hline Bactec Middlebrook & $\begin{array}{l}14 \\
21 \\
32\end{array}$ & $\begin{array}{l}36 \\
36 \\
36\end{array}$ & $\begin{array}{l}11 \\
24 \\
35\end{array}$ \\
\hline Glucose broth & $\begin{array}{l}14 \\
21 \\
32\end{array}$ & $\begin{array}{l}25 \\
36 \\
36\end{array}$ & $\begin{array}{r}0 \\
9 \\
29\end{array}$ \\
\hline Kirschner medium & $\begin{array}{l}14 \\
21 \\
32\end{array}$ & $\begin{array}{l}36 \\
36 \\
36\end{array}$ & $\begin{array}{r}2 \\
16 \\
34\end{array}$ \\
\hline $\begin{array}{l}\text { Isolator lysis } \\
\text { centrifugation } \\
\text { system }\end{array}$ & $\begin{array}{l}14 \\
21 \text { (only } 12 \\
32 \text { tested) }\end{array}$ & $\begin{array}{l}12 \\
12 \\
12\end{array}$ & $\begin{array}{l}11 \\
12 \\
12\end{array}$ \\
\hline Bactec anaerobic & $\begin{array}{l}14 \\
21 \text { (only } 10 \\
32 \text { tested) }\end{array}$ & $\begin{array}{l}0 \\
0 \\
2\end{array}$ & $\begin{array}{l}0 \\
0 \\
0\end{array}$ \\
\hline $\begin{array}{l}\text { Brain heart infusion } \\
\text { broth }\end{array}$ & $\begin{array}{l}14 \\
21 \text { (only } 10 \\
32 \text { tested) }\end{array}$ & $\begin{array}{l}0 \\
0 \\
1\end{array}$ & $\begin{array}{l}0 \\
0 \\
0\end{array}$ \\
\hline
\end{tabular}


$\mathrm{ml})(\mathrm{Gibco})(\mathrm{BH})$ and Bactec anaerobic tryptic soy broth $(30 \mathrm{ml})$ (Becton Dickinson). Volumes of blood inoculated were those recommended by the manufacturers: Isolator $(10 \mathrm{ml})$; Bactec broth, Bactec aerobic medium, BH, digest broth, Kirschner medium (all 5 $\mathrm{ml}$ ); and Bactec Middlebrook medium ( $2 \mathrm{ml}$ ). The five strains of MAI were randomly distributed among the sets.

Radiometric readings were recorded daily from the Bactec bottles. Broth cultures were subcultured on days 3, 6, 8, 13, and 21 on 7H11 agar (Difco) and on a Lowenstein Jensen slope. The subculture plates, sealed inside a plastic bag and incubated at $37^{\circ} \mathrm{C}$ for up to six weeks, were examined daily for mycobacterial growth.

A further simulated laboratory experiment was performed to compare the more promising media. One strain of MAI was used, and four concentrations of the organism in blood were prepared: $550 \mathrm{cfu} / \mathrm{ml}, 55 \mathrm{cfu} /$ $\mathrm{ml}, 5.5 \mathrm{cfu} / \mathrm{ml}$ and $<1 \mathrm{cfu} / \mathrm{ml}$ (average $0.55 \mathrm{cfu} / \mathrm{ml}$ ). Each of these concentrations was inoculated simultaneously into five sets of the following media: Bactec broth, Bactec Middlebrook medium, Kirschner medium, digest broth, Isolator. The deposits from the Isolator tubes containing the lowest concentration of organisms $(<1 \mathrm{cfu} / \mathrm{ml})$ were also inoculated into Bactec Middlebrook medium bottles which were subcultured on 7H11 plates after three days' incubation. The other bottles and tubes were treated the same as in the preliminary study. A Ziehl-Neelson stain was performed on the culture fluid on each day that it was subcultured. Ziehl-Neelson stains were also carried out on all the Isolator deposits at the time of subculture.

\section{CLINICAL COMPARISON OF MEDIA}

All human immunodeficiency virus (HIV) positive patients with a fever had blood taken for culture. At the beginning of the study blood was inoculated into four types of media: digest broth, Bactec broth, Bactec anaerobic medium, and $\mathrm{BH}$. As the study progressed specialised media became available: Bactec Middlebrook medium and Isolator. The digest broth, Bactec broth, Bactec anaerobic medium, and $\mathbf{B H}$ bottles were incubated for a week initially and processed for routine bacteriological culture. At first all these bottles were subcultured directly on 7H11 agar and Lowenstein Jensen slopes for mycobacterial isolation. Later in the study only the Bactec broth, Bactec Middlebrook medium bottles, and Isolator tubes were subcultured for mycobacteria. Subculture was carried out after an incubation period of one week.

Isolates of Mycobacteria were initially identified by their morphology and acid fast properties with the Ziehl-Neelson stain. Further identification and sensitivity testing was kindly performed by the Public Health Laboratory at Dulwich Hospital.

\section{Results}

SIMULATED IN VITRO COMPARISON OF MEDIA The preliminary simulated experiments showed that all the aerobic media, but none of the anaerobic media, supported the growth of MAI.

The Bactec radiometric readings were unreliable in the detection of MAI growth. The Bactec broth bottles gave readings under the positive threshold value despite positive growth on subculture. The Bactec Middlebrook medium often gave high readings immediately after inoculation. This was true of both the simulated preparations and the clinical specimens. There was no statistical difference in the rate of recovery of a heavy inoculum of MAI from the aerobic media tested. A variation in the rate of recovery was much more noticeable with the light inoculum (table 1). In rank order Isolator was the most rapid and sensitive medium. Eleven of 12 tubes yielded a positive growth on subculture by the fourteenth day $(p=0.001)$. This compared with Bactec Middlebrook medium, ranking second, in which 11 of 36 bottles were positive by the fourteenth day, 24 of 36 positive by the twenty first day and 35 of 36 positive by the thirty second day. Isolation of MAI from Bactec Middlebrook medium was statistically greater $(p=0.001)$ at day 14 than from Bactec broth, digest broth, or Kirschner medium.

There was no statistical difference between the performance of Kirschner medium and Bactec aerobic broth. Digest broth performed the least well of all the aerobic media tested, but nevertheless, 29 of 36 bottles yielded growth from the light inoculum by the thirty second day.

In the final simulated laboratory experiment (table 2 ), the Isolator system was the most rapid in detection and isolation at the higher concentrations $(550 \mathrm{cfu} / \mathrm{ml}$ and $55 \mathrm{cfu} / \mathrm{ml}$ ). Acid fast bacilli were detected in the initial centrifuged deposit at day 0 . Culture was also most rapid, colonies being visible on the 7H11 agar plates usually by day 5 . Bactec Middlebrook medium again ranked second.

At the lower concentrations the differences in rate of detection and isolation were more pronounced as in the preliminary studies. Of the liquid media, Bactec Middlebrook medium consistently showed the most rapid rate of detection and isolation. Overall, Isolator was the most rapid method of isolation, but the ZiehlNeelson stains of the centrifuged deposits were negative in all cases. At a concentration of $5.5 \mathrm{cfu} / \mathrm{ml}$, this made Bactec Middlebrook medium the most rapid method of detection as the Ziehl-Neelson stain was positive at day 6 , whereas colonies were not detected on the Isolator subculture plates until day 9.

The sensitivity of most media in recovering MAI suffered at the lowest concentration of $<1 \mathrm{cfu} / \mathrm{ml}$. In 
the liquid media only two of five bottles yielded MAI. MAI were recovered from three Isolator tubes out of five. Sensitivity was noticeably increased by inoculating the Isolator centrifuged deposit into a Bactec

Table 2 Rate of detection of MAI from various culture media

\begin{tabular}{|c|c|c|c|c|}
\hline Media & $550(c f u / m l)$ & $55(\mathrm{cfu} / \mathrm{ml})$ & $5 \cdot 5(c f u / m l)$ & )$<1(\mathrm{cfu} / \mathrm{ml})$ \\
\hline $\begin{array}{l}\text { Bactec aerobic: } \\
\text { Day positive by }\end{array}$ & 6 & 6 & 13 & 21 \\
\hline $\begin{array}{l}\text { Day positive on } \\
\text { culture (range) }\end{array}$ & $\begin{array}{l}11(9-16) \\
5 / 5\end{array}$ & $\begin{array}{l}13(10-15) \\
5 / 5\end{array}$ & $\begin{array}{l}19(17-23) \\
4 / 5\end{array}$ & $\begin{array}{l}32(25-39) \\
2 / 5\end{array}$ \\
\hline \multicolumn{4}{|c|}{ Bactec Middlebrook: } & 13 \\
\hline $\begin{array}{l}\text { Day positive on } \\
\text { culture (range) }\end{array}$ & $\underset{5 / 5}{9(8-10)}$ & $\underset{5 / 5}{9(8-10)}$ & $\begin{array}{l}14(12-18) \\
5 / 5\end{array}$ & $\begin{array}{l}25(16-34) \\
2 / 5\end{array}$ \\
\hline \multicolumn{2}{|l|}{$\begin{array}{l}\text { Glucose broth: } \\
\text { Day positive by }\end{array}$} & 8 & 13 & 21 \\
\hline $\begin{array}{l}\text { Day positive on } \\
\text { culture (range) }\end{array}$ & $\begin{array}{l}15(13-20) \\
5 / 5\end{array}$ & $\begin{array}{l}17(13-22) \\
5 / 5\end{array}$ & $\begin{array}{l}25(16-40) \\
3 / 5\end{array}$ & $\begin{array}{l}36(25-47) \\
2 / 5\end{array}$ \\
\hline Kirschner medium: & $\begin{array}{l}\mathrm{m}: \\
6\end{array}$ & 6 & 13 & 21 \\
\hline $\begin{array}{l}\text { Day positive on } \\
\text { culture (range) }\end{array}$ & $\begin{array}{l}12(10-15) \\
5 / 5\end{array}$ & $\begin{array}{l}13(10-15) \\
5 / 5\end{array}$ & $\begin{array}{l}17(16-22) \\
4 / 5\end{array}$ & $\begin{array}{l}29(23-39) \\
2 / 5\end{array}$ \\
\hline \multicolumn{5}{|c|}{ Isolator lysis centrifugation system: } \\
\hline $\begin{array}{l}\text { Day positive by } \\
\text { Ziehl-Neelson }\end{array}$ & 0 & $\mathbf{0}$ & negative & negative \\
\hline culture (range) & $\underset{5 / 5}{5(5)}$ & $\begin{array}{c}5(5) \\
5 / 5\end{array}$ & $\underset{5 / 5}{9(6-13)}$ & $\begin{array}{l}15(11-18) \\
3 / 5\end{array}$ \\
\hline \multicolumn{5}{|c|}{ Isolator lysis centrifugation system + Bactec Middlebrook: } \\
\hline $\begin{array}{l}\text { Ziehl-Neelson } \\
\text { Day positive on }\end{array}$ & ND & ND & ND & negative \\
\hline culture (range) & ND & ND & ND & $\begin{array}{l}14(11-15) \\
5 / 5\end{array}$ \\
\hline
\end{tabular}

Middlebrook medium bottle, and incubating these for three days before subculture.
CLINICAL COMPARISON OF MEDIA

Between January 1986 and July 1987 one hundred and thirty seven HIV positive patients had blood taken for culture. A total of 306 blood culture bottles were processed for mycobacterial culture. Mycobacterial growth was observed in 48 bottles from $13(9.5 \%)$ patients. MAI was never isolated from one aerobic medium and not from another (table 3 ). They were equally sensitive. None of the anaerobic media subcultured for mycobacteria yielded any growth. The difference between the aerobic media lay in the rate of isolation.

It took longer to isolate MAI from clinical specimens than from the simulated preparations. Detection in some cases was rapid, acid fast bacilli being detected from the Bactec Middlebrook medium broth on day 7 (case 12), and in another case from the Bactec Middlebrook medium and Bactec broth on day 8 (case 6). Isolation was clearly most rapid using the Isolator system (cases 2 and 3 ). In both these cases MAI was isolated from the Isolator tubes over 10 days before the broth subcultures yielded growth.

\section{Discussion}

MAI infection in patients with AIDS in the United Kingdom seems to be as common as in the United States of America. ${ }^{1-5}$ It is therefore important for all microbiology departments dealing with specimens from this group of patients to be in a position to isolate MAI from blood cultures. Early detection of MAI infection assists with the rapid diagnosis of opportunistic infection in patients with AIDS. It also allows prompt initiation of anti-mycobacterial treatment, although at present the value of this treatment is limited.

MAI is not a fastidious organism. It grows well in a variety of commercially available media, and, as has been shown in this study, MAI may be isolated from conventional blood culture media such as glucose

Table 3 Day of detection of MAI from clinical samples

\begin{tabular}{|c|c|c|c|c|c|}
\hline \multirow[b]{2}{*}{ Case No } & \multicolumn{2}{|l|}{ Bactec aerobic } & \multicolumn{2}{|c|}{ Bactec Middlebrook } & Other media \\
\hline & Ziehl-Neelson & Culture & Ziehl-Neelson & Culture & Ziehl-Neelson \\
\hline $\begin{array}{r}1 \\
2 \\
3 \\
4 \\
5 \\
6 \\
7 \\
8 \\
9 \\
10 \\
11 \\
12 \\
13\end{array}$ & $\begin{array}{l}15 \\
19 \\
20 \\
8 \\
\\
10 \\
13 \\
12 \\
\text { Negative } \\
\text { Negative }\end{array}$ & $\begin{array}{l}33 \\
\text { Not tested } \\
39 \\
29 \\
\text { Not tested } \\
25 \\
38 \\
\text { Not tested } \\
21 \\
22 \\
33 \\
31 \\
33\end{array}$ & $\begin{array}{l}16 \\
17 \\
\text { Negative } \\
8 \\
\text { Negative } \\
13 \\
7\end{array}$ & $\begin{array}{l}\text { Not tested } \\
28 \\
37 \\
\text { Not tested } \\
40 \\
25 \\
\text { Not tested } \\
46 \\
\text { Not tested } \\
22 \\
\text { Not tested } \\
27 \\
\text { Not tested }\end{array}$ & $\begin{array}{ll}\text { Negative Isolator } & 17 \\
\text { Negative Isolator } & 20 \\
20 \quad \text { glucose broth } 29 \\
\end{array}$ \\
\hline
\end{tabular}


broth and Bactec aerobic media. Anaerobic media do not support the growth of MAI, and they should not be used. Specialised blood culture systems are not essential for the isolation of MAI, but may speed up the rate of detection.

Both the simulated laboratory and the clinical comparison of media has shown a noticeable variation in the rate and sensitivity of various blood culture media to detect MAI, particularly when there was a light inoculum of organisms. The Isolator system was consistently the most rapid method of isolation. MAI is an intracellular parasite. The ability of the Isolator system to lyse blood cells and neutralise the antibacterial properties of blood promotes the isolation of these organisms. The Isolator system has the added advantage of being simple to handle and process. When blood is being collected for culture, the Isolator tubes can be inserted into a Vacutainer sheath. The use of needles is minimised for both the clinician and the laboratory technician.

The growth index readings were not a reliable indicator of positive mycobacterial growth in the radiometric bottles. MAI grows rapidly in the Bactec Middlebrook medium, and, where low inocula are present, this method may provide the most rapid detection rate, as Ziehl-Neelson staining of the broth may show acid fast bacilli.

For the most rapid and sensitive method for the isolation of MAI from blood, we recommend collecting the blood in Isolator tubes. Half the deposit should be subcultured on Middlebrook $7 \mathrm{H} 11$ agar and a Lowenstein Jensen slope, and the other half should be inoculated into Bactec Middlebrook media, which should be subcultured on solid media after three to five days. For those laboratories which do not have access to these specialised blood culture methods, conventional blood culture techniques should yield MAI if present, but the incubation period may need to be extended. (Further details of the Bactec readings and details of the techniques referred to in the text can be obtained from the authors).

\section{References}

1 Gill VJ, Park CH, Stock F, Gosey LL, Witebsky FG, Masur H. Use of lysis-centrifugation (Isolator) and radiometric (BACTEC) blood culture systems for the detection of mycobacteremia. J Clin Microbiol 1985;22:543-6.

2 Hawkins CC, Gold JWM, Whimbey $\mathrm{H}$, et al. Mycobacterium avium complex infections in patients with the acquired immunodeficiency syndrome. Ann Intern Med 1986;105:184-8.

3 Greene JB, Sidhu GS, Lewin S, et al. Mycobacterium aviumintracellulare: a cause of disseminated life-threatening infection in homosexuals and drug abusers. Ann Intern Med 1982;97: 539-46.

4 Kiehn TE, Edwards FF, Brannon P, et al. Infections caused by Mycobacterium avium complex in immunocompromised patients: diagnosis by blood culture and fecal examination, antimicrobial susceptibility tests, and morphological and seroagglutination characteristics. J Clin Microbiol 1985;21: 168-73.

5 Young LS, Inderlied CB, Berlin OG, Gottlieb MS. Mycobacterial Infections in AIDS patients, with an emphasis on the Mycobacterium avium complex. Rev Infect Dis 1986;8:1024-33.

Requests for reprints to: Dr D C Shanson, Consultant Microbiologist, St Stephen's Hospital, Fulham Road, London SW10 9TH, England. 